\title{
SPC for Software Reliability using Inflection S-Shaped Model
}

\author{
R.Satya Prasad, PhD. \\ Associate Professor \\ Dept.of Computer Science \& Engg., \\ Achrya Nagarjuna University \\ Guntur
}

\author{
Y.Sangeetha \\ Asst.Professor \\ Dept.of Information Technology \\ V.R.Siddhartha Engg.College \\ Vijayawada
}

\begin{abstract}
Traditional statistical analysis methods account for natural variation but require aggregation of measurements over time, which can delay decision making.Statistical process control (SPC) is a branch of statistics that combines rigorous time series analysis methods with graphical presentation of data,often yielding insights into the data more quickly and in a way more understandble to lay decision makers .SPC and its primary tool-the control chart-provide researchers and practitioners with a method of better understanding and communicating data from software reliability improvement process efforts .This paper provides an s-shaped software reliability growth model based on the Non-Homogenous Poisson Process (NHPP).The maximum likelihood approach is used to estimate the unknown parameters of the model.
\end{abstract}

Keywords: Statistical Process Control, software reliability, mean value function, probability limits, control charts, Inflection s-shaped.

\section{INTRODUCTION}

Software reliability is a key part in software quality. The study of software reliability can be categorized into three parts: modeling, measurement and improvement. Software reliability modeling has matured to the point that meaningful results can be obtained by applying suitable models to the problem. There are many models that exist, but no single model can capture a necessary amount of the software characteristics. Assumptions and abstractions must be made to simplify the problem. There is no single model that is universal to all the situations. Software reliability cannot be directly measured, so other related factors are measured to estimate software reliability and compare it among products. Development process, faults and failures found are all factors related to software reliability. Software reliability improvement is complex process. The difficulty of the problem stems from insufficient understanding of software reliability and in general, the characteristics of software. Until now there is no good way to conquer the complexity problem of software the difficulty of the problem stems from insufficient understanding of software reliability. The difficulty of the problem stems from insufficient understanding of software reliability and in general, the characteristics of software. Until now there is no good way to conquer the complexity problem of software. Defect-free software product cannot be assured. Realistic constraints of time and budget severely limit the effort put into software reliability improvement. Software quality and reliability must be made to simplify the problem. There is no single model that is universal to all the situations. Software reliability cannot be directly measured, so other related factors are measured to estimate software reliability and compare it among products.
Software quality and reliability can be achieved by eliminating the causes or improving the software process or its operating procedures [2].Applying statistical process control (use of control charts) to the management of software development efforts, to effect software process improvement. Deploying Statistical Process Control is a process in itself, requiring organizational commitment across functional boundaries. SPC procedures can help you monitor process behavior [13]. The SPC chart selection is based on data, situation and need [4].Control charts are an efficient way of analyzing performance data in order to evaluate a process. A control chart is a popular statistical tool for monitoring the quality of goods and services, and for detecting when the process goes "out of control" as early as possible. The data from measurements of variations at points on the process map is monitored using control charts. Using control charts is a continuous activity, ongoing over time. Considering above, software reliability measurement is a complex process which needs rational reliability models.

\section{NHPP MODEL}

The Non-Homogenous Poisson Process (NHPP) based software reliability growth models (SRGMs) are proven to be quite successful in practical software reliability engineering [1, 3,12]. The main issue in the NHPP model is to determine an appropriate mean value function to denote the expected number of failures experienced up to a certain time point. Model parameters can be estimated by using Maximum Likelihood Estimate (MLE).

Let $\{N(t), t \geq 0\}$ be the cumulative number of software failures by time' $t$ '. $m(t)$ is the mean value function, representing the expected number of software failures by time ' $\mathrm{t}$ '. $\lambda(t)$ Is the failure intensity function, which is proportional to the residual fault content. Thus $m(t)=a\left(1-e^{-b t}\right)$ and $\lambda(t)=\frac{d m(t)}{d t}=b(a-m(t))$. where 'a' denotes the initial number of faults contained in a program and ' $b$ '

represents the fault detection rate. In software reliability, the initial number of faults and the fault detection rate are always unknown. The maximum likelihood technique can be used to evaluate the unknown parameters. In a more general NHPP SRGM $\lambda(t)$ can be expressed as $\lambda(t)=\frac{d m(t)}{d t}=b(t)[a(t)-m(t)]$. Where $a(t)$ is the time-dependent fault content function which includes the initial 
and introduced faults in the program and $b(t)$ is the time-dependent fault detection rate.

\section{MODEL DESCRIPTION: INFLECTION S-SHAPED MODEL}

Software reliability growth models have been grouped into two classes of models concave and S-shaped. The most important thing about both models is that they have the same asymptotic behavior, i.e., the defect detection rate decreases as the number of defects detected (and repaired) increases, and the total number of defects detected asymptotically approaches a finite value. The inflection $\mathrm{S}$-shaped model was proposed by $[5,6]$. This model assumes that the fault detection rate increases throughout a test period. The model has a parameter, called the inflection rate, which indicates the ratio of detectable faults to the total number of faults in the target software. True, sustained exponential growth cannot exist in the real world. Eventually all exponential, amplifying processes will uncover underlying stabilizing processes that act as limits to growth. The shift from exponential to asymptotic growth is known as sigmoidal, or S-shaped, growth.

Ohba models the dependency of faults by postulating the following assumptions:

- Some of the faults are not detectable fore some other faults are removed.

- The detection rate is proportional to the number of detectable faults in the program.

- Failure rate of each detectable fault is constant and identical.

- All faults can be removed.

Assuming [7]: $b(t)=\frac{b}{1+\beta e^{-b t}}$

This model is characterized by the following mean value function:

$$
m(t)=\frac{a}{1+\beta e^{-b t}}\left(1-e^{-b t}\right)
$$

Where ' $b$ ' is the failure detection rate, and ' $\boldsymbol{\beta}$ ' is the inflection factor. The failure intensity function is given as: $\lambda(t)=\frac{a b e^{-b t}(1+\beta)}{\left(1+\beta e^{-b t}\right)^{2}}$

\section{PARAMETER ESTIMATION: MLE}

The idea behind maximum likelihood parameter estimation is to determine the parameters that maximize the probability (likelihood) of the sample data. The method of maximum likelihood is considered to be more robust (with some exceptions) and yields estimators with good statistical properties. In other words, MLE methods are versatile and apply to most models and to different types of data. Although the methodology for maximum likelihood estimation is simple, the implementation is mathematically intense. Using today's computer power, however, mathematical complexity is not a big obstacle. Conduct an experiment and obtain $\mathrm{N}$ independent observations, $t_{1}, t_{2}, \ldots, t_{N}$. Then the likelihood function [9] is given by the following product: $L\left(t_{1}, t_{2}, \ldots, t_{N} \mid \theta_{1}, \theta_{2}, \ldots, \theta_{k}\right)=L=\prod_{i=1}^{N} f\left(t_{i} ; \theta_{1}, \theta_{2}, \ldots, \theta_{k}\right)$

Likely hood function by using $\lambda(\mathrm{t})$ is: $\mathrm{L}=$ $\prod_{i=1}^{n} \lambda\left(t_{i}\right) \quad$ The logarithmic likelihood function is given by: $\Lambda=\ln L=\sum_{i=1}^{N} \ln f\left(t_{i} ; \theta_{1}, \theta_{2}, \ldots, \theta_{k}\right) \quad$ Log Likelihood function is: $\log \mathrm{L}=\log \left(\prod_{i=1}^{n} \lambda\left(t_{i}\right)\right)$

Which can be written [10] as $\sum_{i=1}^{n}\left(y_{i}-y_{i-1}\right) \cdot \log \left[m\left(t_{i}\right)-m\left(t_{i-1}\right)\right]-m\left(t_{n}\right)$

The maximum likelihood estimators (MLE) of $\theta_{1}, \theta_{2}, \ldots, \theta_{k}$ are obtained by maximizing $L$ or $\Lambda$, where $\Lambda$ is in $L$. By maximizing $\Lambda$, which is much easier to work with than $L$, the maximum likelihood estimators (MLE) of $\theta_{1}, \theta_{2}, \ldots, \theta_{k}$ are the simultaneous solutions of $k$ equations such that:

$$
\frac{\partial(\Lambda)}{\partial \theta_{j}}=0, \quad \mathrm{j}=1,2, \ldots, \mathrm{k}
$$

The parameters ' $a$ ' and ' $b$ ' are estimated using iterative Newton Raphson Method, which is given as $x_{n+1}=x_{n}-\frac{f\left(x_{n}\right)}{f^{\prime}\left(x_{n}\right)}$

\section{ILLUSTRATING THE MLE METHOD PARAMETER ESTIMATION}

To estimate 'a' and ' $b$ ', for a sample of $n$ units, first obtain the likelihood function: assuming $\beta=0.05$.

$$
L=\prod_{i=1}^{N} \frac{a b e^{-b t}(1+\beta)}{\left(1+\beta e^{-b t}\right)^{2}}
$$

Take the natural logarithm on both sides, The Log Likelihood function is given as:

$$
\log \mathrm{L} \quad=\log \left[\prod_{i=1}^{n} \lambda\left(t_{i}\right)\right]
$$




$$
\begin{gathered}
=\log \left[\prod_{i=1}^{n} \frac{a b e^{-b t}(1+\beta)}{\left(1+\beta e^{-b t}\right)^{2}}\right. \\
\sum_{i=1}^{n} \log \left(\frac{a b e^{-b t}(1+\beta)}{\left(1+\beta e^{-b t}\right)^{2}}\right)-\frac{a}{1+\beta e^{-b t}}\left(1-e^{-b t}\right)
\end{gathered}
$$

Taking the Partial derivative w.r.t ' $a$ ' and equating to ' 0 '. (i.e. $\frac{\partial \log L}{\partial a}=0$ )

$\mathrm{a}=\frac{\left(n_{k}-n_{0}\right)\left(1+\beta e^{-b t_{k}}\right)}{1-e^{-b_{k}}}$

Taking the Partial derivative w.r.t ' $b$ ' and equating to '0'.(i.e.

$g(b)=\frac{\partial \log L}{\partial b}=0$ )

$\mathrm{g}(\mathrm{b})=\sum_{i=1}^{n}\left(y_{i}-y_{i-1}\right)\left[\left(\frac{t_{i} e^{-b t_{i}}-t_{i-1} e^{-b t_{i-1}}}{e^{-b t_{i-1}-e^{-b t_{i}}}}\right)+\left(\frac{\beta t_{i} e^{-b t_{i}}}{1+\beta e^{-b t_{i}}}\right)+\right.$ $\beta t i-1 e-b t i-11+\beta e-b t i-1-$

nktke-btk1- $\beta+2 \beta e-b t k 1-e-b t k 1+\beta e-b t k$. ........(5.2)

Taking the partial derivative again w.r.t ' $b$ ' and equating to ' 0 '.

(i.e. $g^{\prime}(b)=\frac{\partial^{2} \log L}{\partial b^{2}}=0$ )

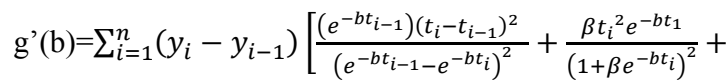

$\left.\frac{\beta t_{i-1}^{2} e^{-b t_{i-1}}}{\left(1+\beta e^{-b t_{i-1}}\right)^{2}}\right]$ $\frac{n_{k} t_{k} e^{-b t_{k}}\left[e^{-b t_{k}}\left(1-\beta+2 \beta e^{-b t_{x}}\right)^{2}+\left(1-e^{-b t_{x}}\right)\left(1+\beta e^{-b t_{x}}\right)\left(1-\beta+4 \beta e^{-b t_{x}}\right)\right]}{\left(\left(1-e^{-b t_{x}}\right)\left(1+\beta e^{-b t_{x}}\right)\right)^{2}}$

The parameter ' $\mathrm{b}$ ' is estimated by iterative Newton Raphson Method using $b_{n+1}=b_{n}-\frac{g\left(b_{n}\right)}{g^{\prime}\left(b_{n}\right)}$, which is substituted in finding ' $a$ '.

\section{DISTRIBUTION OF FAILURE COUNT DATA}

Based on the failure count data given in Table $1 \& 2$, we compute the software failures process through Mean Value Control chart. We used cumulative Failure count data for software reliability monitoring using inflection s-shaped distribution.

Assuming an acceptable probability of false alarm of $0.27 \%$, the control limits are calculated by solving the following equations.

$$
\begin{aligned}
& T_{U}=\frac{1}{1+\beta e^{-b t}}\left(1-e^{-b t}\right)=0.99865 \\
& T_{C}=\frac{1}{1+\beta e^{-b t}}\left(1-e^{-b t}\right)=0.5
\end{aligned}
$$$$
T_{L}=\frac{1}{1+\beta e^{-b t}}\left(1-e^{-b t}\right)=0.00135
$$

Table 1: Failure count data, DS1

\begin{tabular}{|l|l|l|l|l|l|}
\hline $\begin{array}{l}\text { Failure } \\
\text { Number }\end{array}$ & $\begin{array}{l}\text { No. of fail- } \\
\text { ures }\end{array}$ & $\begin{array}{l}\text { Failure } \\
\text { Number }\end{array}$ & $\begin{array}{l}\text { No. of fail- } \\
\text { ures }\end{array}$ & $\begin{array}{l}\text { Failure } \\
\text { Number }\end{array}$ & $\begin{array}{l}\text { No. of fail- } \\
\text { ures }\end{array}$ \\
\hline 1 & 2 & 8 & 1 & 15 & 1 \\
\hline 2 & 1 & 9 & 7 & 16 & 6 \\
\hline 3 & 1 & 10 & 3 & 17 & 1 \\
\hline 4 & 1 & 11 & 1 & 18 & 3 \\
\hline 5 & 2 & 12 & 2 & 19 & 1 \\
\hline 6 & 2 & 13 & 2 & 20 & 3 \\
\hline 7 & 2 & 14 & 4 & 21 & 1 \\
\hline
\end{tabular}


Table 2: Failure count data, DS2

\begin{tabular}{|l|l|l|l|l|l|}
\hline $\begin{array}{l}\text { Failure } \\
\text { Number }\end{array}$ & $\begin{array}{l}\text { No. of fail- } \\
\text { ures }\end{array}$ & $\begin{array}{l}\text { Failure } \\
\text { Number }\end{array}$ & $\begin{array}{l}\text { No. of fail- } \\
\text { ures }\end{array}$ & $\begin{array}{l}\text { Failure } \\
\text { Number }\end{array}$ & $\begin{array}{l}\text { No. of fail- } \\
\text { ures }\end{array}$ \\
\hline 1 & 6 & 8 & 3 & 15 & 5 \\
\hline 2 & 2 & 9 & 2 & 16 & 2 \\
\hline 3 & 1 & 10 & 3 & 17 & 2 \\
\hline 4 & 1 & 11 & 1 & 18 & 2 \\
\hline 5 & 3 & 12 & 3 & 19 & 1 \\
\hline 6 & 1 & 13 & 2 & 20 & 3 \\
\hline 7 & 2 & 14 & 5 & & \\
\hline
\end{tabular}

' $\hat{a}$ ' and ' $\hat{b}$ ' are Maximum Likely hood Estimates (MLEs) of parameters and the values can be computed using iterative method for the given cumulative time between failures data shown in Table $1 \& 2$. Using ' $a$ ' and 'b' values we can compute $m(t)$.

$$
\text { These limits are converted to } m\left(t_{U}\right), m\left(t_{C}\right) \text { and }
$$

$m\left(t_{L}\right)$ form. They are used to find whether the software pro- cess is in control or not by placing the points in Mean value chart shown in figure $1 \& 2$. A point below the control limit $m\left(t_{L}\right)$ indicates an alarming signal. A point above the control limit $m\left(t_{U}\right)$ indicates better quality. If the points are falling within the control limits it indicates the software process is in stable

[8].

Table 3: Estimated parameters and the corresponding control limits

\begin{tabular}{|l|l|l|l|l|l|}
\hline Data set & A & $\mathbf{b}$ & $\mathbf{m}\left(\mathbf{t}_{\mathbf{u}}\right)$ & $\mathbf{m}\left(\mathbf{t}_{\mathbf{c}}\right)$ & $\mathbf{m}\left(\mathbf{t}_{\mathbf{l}}\right)$ \\
\hline DS1 & 871.823132 & 0.002646 & 869.880070 & 435.878051 & 1.176445 \\
\hline DS2 & 2664.972820 & 0.000874 & 2660.57464 & 1332.21952 & 3.59737 \\
\hline
\end{tabular}

Table 4: DS1-Successive differences of cumulative mean values.

\begin{tabular}{|l|l|l|l|l|l|l|l|}
\hline No & $\begin{array}{l}\text { Cum } \\
\text { Failures }\end{array}$ & $\mathbf{m}(\mathbf{t})$ & $\begin{array}{l}\text { Succes- } \\
\text { sive dif- } \\
\text { ferences }\end{array}$ & No & $\begin{array}{l}\text { Cum } \\
\text { Failures }\end{array}$ & $\mathbf{m}(\mathbf{t})$ & $\begin{array}{l}\text { Successive } \\
\text { differences }\end{array}$ \\
\hline $\mathbf{1}$ & 2 & 4.380758 & 2.181700 & $\mathbf{1 2}$ & 25 & 53.255941 & 4.179178 \\
\hline $\mathbf{2}$ & 3 & 6.562459 & 2.1759357 & $\mathbf{1 3}$ & 27 & 57.435119 & 8.165291 \\
\hline $\mathbf{3}$ & 4 & 8.7383948 & 2.170185 & $\mathbf{1 4}$ & 31 & 65.600411 & 2.0278552 \\
\hline $\mathbf{4}$ & 5 & 10.908580 & 4.341534 & $\mathbf{1 5}$ & 32 & 67.628266 & 12.150753 \\
\hline $\mathbf{5}$ & 7 & 15.250114 & 4.305545 & $\mathbf{1 6}$ & 38 & 79.779019 & 1.993030 \\
\hline $\mathbf{6}$ & 9 & 19.555660 & 4.282821 & $\mathbf{1 7}$ & 39 & 81.772050 & 5.947548 \\
\hline $\mathbf{7}$ & 11 & 23.838481 & 2.132926 & $\mathbf{1 8}$ & 42 & 87.719598 & 1.972047 \\
\hline $\mathbf{8}$ & 12 & 25.971407 & 14.822531 & $\mathbf{1 9}$ & 43 & 89.691646 & 5.884931 \\
\hline $\mathbf{9}$ & 19 & 40.793938 & 6.255731 & $\mathbf{2 0}$ & 46 & 95.576578 & 1.951285 \\
\hline $\mathbf{1 0}$ & 22 & 47.049670 & 2.074233 & $\mathbf{2 1}$ & 47 & 97.527863 & \\
\hline $\mathbf{1 1}$ & 23 & 49.123903 & 4.132037 & & & & \\
\hline
\end{tabular}


Table 5: DS2-Successive differences of cumulative mean values.

\begin{tabular}{|l|l|l|l|l|l|l|l|}
\hline No & $\begin{array}{l}\text { Cum } \\
\text { Failures }\end{array}$ & $\mathbf{m}(\mathbf{t})$ & $\begin{array}{l}\text { Successive } \\
\text { differences }\end{array}$ & No & $\begin{array}{l}\text { Cum } \\
\text { Failures }\end{array}$ & $\mathbf{m}(\mathbf{t})$ & $\begin{array}{l}\text { Successive } \\
\text { differences }\end{array}$ \\
\hline $\mathbf{1}$ & 6 & 13.274436 & 4.412048 & $\mathbf{1 9}$ & 47 & 102.304655 & 6.403911 \\
\hline $\mathbf{2}$ & 8 & 17.683801 & 2.203407 & $\mathbf{2 0}$ & 50 & 108.746510 & 4.260806 \\
\hline $\mathbf{3}$ & 9 & 19.893430 & 2.201664 & $\mathbf{2 1}$ & 52 & 113.007316 & 8.501331 \\
\hline $\mathbf{4}$ & 10 & 22.094167 & 6.594546 & $\mathbf{2 2}$ & 56 & 121.508647 & 2.121115 \\
\hline $\mathbf{5}$ & 13 & 28.684850 & 2.194704 & $\mathbf{2 3}$ & 57 & 123.629762 & 4.237176 \\
\hline $\mathbf{6}$ & 14 & 30.877907 & 4.384199 & $\mathbf{2 4}$ & 59 & 127.866938 & 4.230447 \\
\hline $\mathbf{7}$ & 16 & 35.258275 & 6.563293 & $\mathbf{2 5}$ & 61 & 132.097385 & 4.223727 \\
\hline $\mathbf{8}$ & 19 & 41.830956 & 4.366872 & $\mathbf{2 6}$ & 63 & 136.321112 & 2.109346 \\
\hline $\mathbf{9}$ & 21 & 46.193941 & 6.537349 & $\mathbf{2 7}$ & 64 & 138.430458 & 4.213664 \\
\hline $\mathbf{1 0}$ & 24 & 52.724136 & 2.175665 & $\mathbf{2 8}$ & 66 & 142.644122 & 4.206968 \\
\hline $\mathbf{1 1}$ & 25 & 54.897065 & 6.516660 & $\mathbf{2 9}$ & 68 & 146.851090 & 4.200281 \\
\hline $\mathbf{1 2}$ & 28 & 61.404470 & 4.335839 & $\mathbf{3 0}$ & 70 & 151.051372 & 4.193604 \\
\hline $\mathbf{1 3}$ & 30 & 65.759150 & 10.809563 & $\mathbf{3 1}$ & 72 & 155.244976 & 6.277907 \\
\hline $\mathbf{1 4}$ & 35 & 76.552352 & 10.766780 & $\mathbf{3 2}$ & 75 & 161.522883 & 2.089308 \\
\hline $\mathbf{1 5}$ & 40 & 87.332847 & 4.294767 & $\mathbf{3 3}$ & 76 & 163.612191 & 4.173630 \\
\hline $\mathbf{1 6}$ & 42 & 91.619857 & 4.287955 & $\mathbf{3 4}$ & 78 & 167.785821 & 2.084325 \\
\hline $\mathbf{1 7}$ & 44 & 95.899380 & 4.281153 & $\mathbf{3 5}$ & 79 & 169.870145 & \\
\hline $\mathbf{1 8}$ & 46 & 100.171429 & 2.138029 & & & & \\
\hline & & & & & & & \\
\hline
\end{tabular}

By placing the differences of cumulative failure counts shown in table 4 and 5 on y axis, failure number on $\mathrm{x}$ axis and the values of control limits being placed on Mean Value chart, we obtained figure $1 \& 2$. The first Mean Value chart shows that all the mean value successive differences are within the control limits, which indicates that the process is in stable state. Whereas the in the second chart some of the successive differences are out of control limits, which indicates the failure process is identified. It is significantly early detection of failures using Mean Value Chart [11]. The software quality is determined by detecting failures at an early stage.

\section{mean value chart}

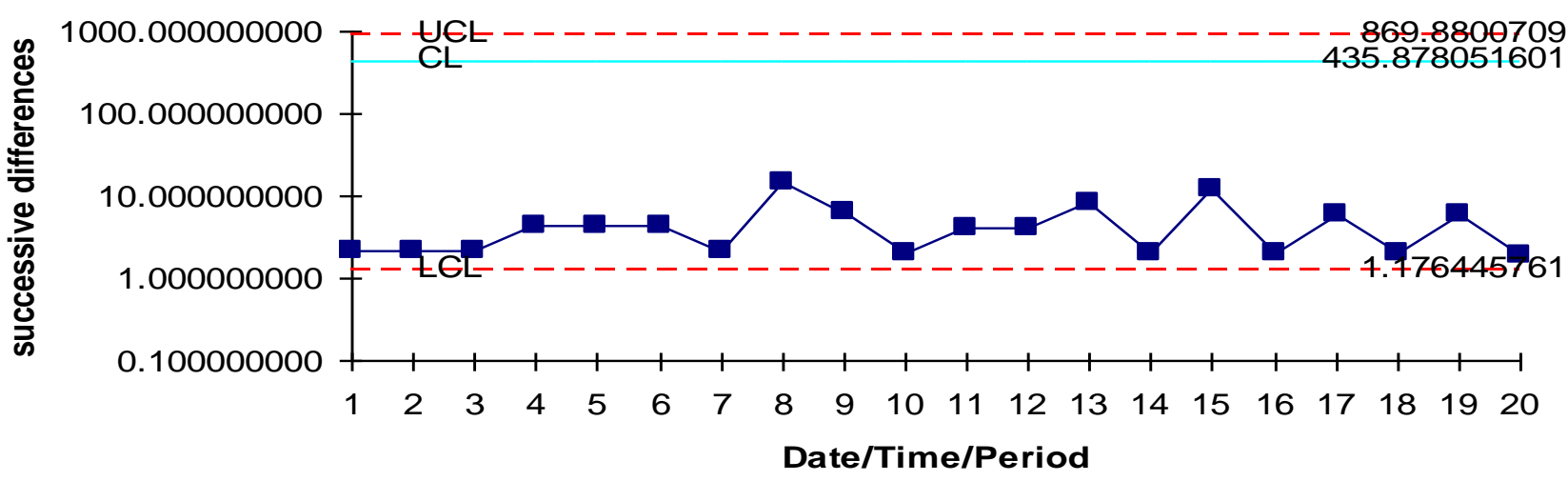

Figure: 1 Mean Value Chart for DS1 


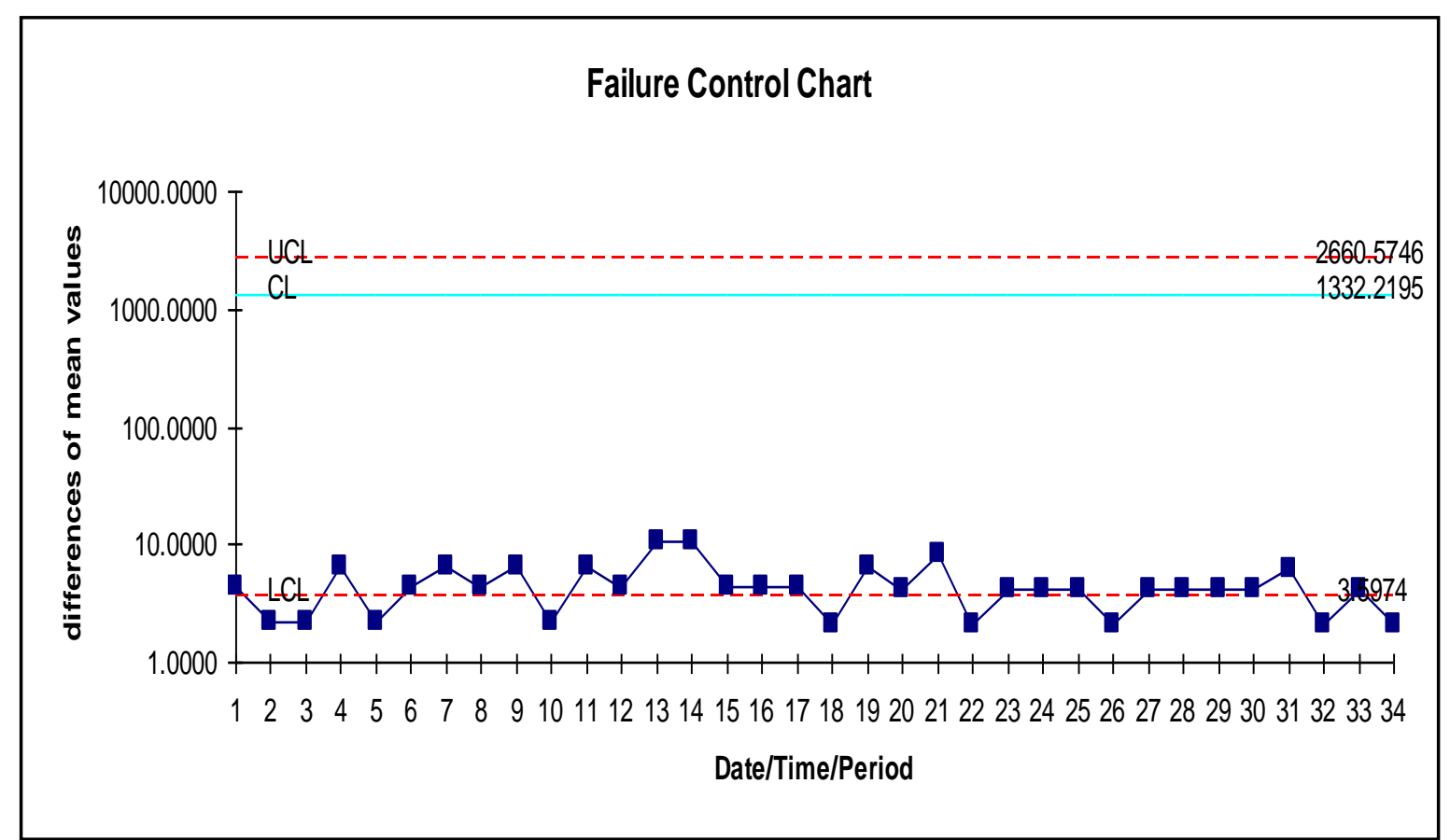

Figure: 2 Mean Value Chart for DS2

\section{CONCLUSION}

The successive differences of failure counts are plotted through the estimated mean value function against the failure serial order. The parameter estimation is carried out by Newton Raphson Iterative method for inflection s-shaped model. The graph of data set DS1 in figure 1 has shown all the points with in control limits .By observing the Mean Value Control chart of data set DS2, it is identified that failure situation is detected at $2^{\text {nd }}$ point , which is below $\mathrm{m}\left(t_{L}\right)$.It indicates that the failure process is detected at an early stage. Hence we conclude that our method of estimation and control chart are giving a positive recommendation for their use in finding out preferable control process or desirable out of control signal .The early detection of software failure will improve the software reliability.

\section{REFERENCE}

[1] Geetha Rani, N., Satya Prasad, R., \& Kantham, R.R.L., (2011).Software Reliability Growth Model Using Interval Domain Data. International Journal of Computer Applications, Vol 34[9], Pp.5-8.

[2] Kimura, M., Yamada, S., Osaki, S., (1995).Statistical Software Reliability prediction and Its Applicability Based on Mean Time Between Failures. Mathematical and Computer Modeling, Vol 22, Issues 10-12, Pp. 149155 .

[3] Krishna Mohan G., \& Satya Prasad, R., (2011). Interval Domain Based Software Process Control Using Weibull Mean Value Function. International Journal of Computer Science and Information Technology and Security, Vol 1[2], Pp.111-114.
[4] Macgregor, J.F., Kourti, T., (1995).Statistical Process Control of Multivariate Processs.Control Engineering Practice, Vol 3, Issue 3, Pp.403-414, Canada: Elsevier.

[5] Ohba, M., (1984). Software Reliability Analysis Model. IBM J. Res. Develop, Vol 28, Pp.428-443.

[6] Ohba, M., (1984a). Software Reliability Analysis Models. IBM Journal Research Development, Vol.21 (4).

[7] Ohba, M., \& Yamada, S., (1984b). S-Shaped Software Reliability Growth Models .Proc. $4^{\text {th }}$ Int.Conf.Reliabilit and Maintainability, Pp.430-436.

[8] Pham. H., (1993). Software Reliability Assessment: Imperfect Debugging and Multiple Failure types Software Development. EG\&GRAAM-10737, Salt Lake: Idaho National Engineering Laboratory.

[9] Pham. H., (2003). Handbook of Reliability Engineering, London: Springer.

[10] Pham. H., (2006). System software reliability, London: Springer.

[12] Satya Prasad, R., Gotham, V., \& Krishna Mohan G., (2011). Interval Domain Software Process Control Goelokumoto. International Journal of Research and Reviews in Computer Science, Vol 2[4], Pp.1001-1004.

[13] Xie, M., Goh. T.N., \& Ranjan, P., (2002). Some Effective Control Chart Procedures for Reliability Monitoring.Reliability engineering and System Safety, Vol 77, Pp.143-150. 